\title{
Genetic and Environmental Contributions to the Relationship Between Internalizing Disorders and Sick Leave Granted for Mental and Somatic Disorders
}

\author{
Fartein A. Torvik, ${ }^{1}$ Line C. Gjerde, ${ }^{1}$ Espen Røysamb, ${ }^{1,2}$ Kristian Tambs, ${ }^{1}$ Kenneth S. Kendler, ${ }^{3,4}$ \\ Nikolai O. Czajkowski, ${ }^{1,2}$ Gun P. Knudsen, ${ }^{1}$ Ted Reichborn-Kjennerud, ${ }^{1,5}$ and Ragnhild E. Ørstavik ${ }^{1}$ \\ ${ }^{1}$ Division of Mental Health, Norwegian Institute of Public Health, Oslo, Norway \\ ${ }^{2}$ Department of Psychology, University of Oslo, Oslo, Norway \\ ${ }^{3}$ Department of Psychiatry, Virginia Commonwealth University, Richmond, VA, USA \\ ${ }^{4}$ Virginia Institute for Psychiatric and Behavioral Genetics, Virginia Commonwealth University, Richmond, VA, USA \\ ${ }^{5}$ Institute of Clinical Medicine, University of Oslo, Oslo, Norway
}

\begin{abstract}
This study investigates the degree to which internalizing disorders (anxiety and mood disorders) are prospectively associated with sick leave granted for mental and somatic disorders, and the extent to which common genetic and environmental risk factors influence these relationships. Data include selfreported symptoms of psychological distress from 7,598 young adult twins and diagnostic interviews on a subsample of 2,766 adult twins, subsequently linked to registry data on sick leave. Regression analyses and multivariate twin models were used to investigate the relationship between internalizing disorders and sick leave. Internalizing disorders were associated with sick leave granted for both mental disorders and somatic disorders. The association between internalizing disorders and sick leave granted for mental disorders was influenced by genetic and non-shared environmental factors, while the association between internalizing disorders and sick leave granted for somatic disorders could be explained by common genetic factors alone. Monozygotic twins discordant for internalizing disorders differed significantly in rates of sick leave granted for mental but not somatic disorders. In conclusion, internalizing disorders in young adults predict sick leave granted for both mental and somatic disorders. Environmental risk factors for internalizing disorders seem to influence sick leave granted for mental disorders, but not sick leave granted for somatic disorders.
\end{abstract}

Keywords: sick leave, anxiety, depression, genetic epidemiology, twin study

Sick leave is an economic burden for workplaces and societies due to lost productivity (OECD, 2010). In Norway, $6.3 \%$ of working days are lost to sick leave, more than in most industrialized countries (Osterkamp \& Röhn, 2005; Statistics Norway, 2013). Sick leave can lead to disability pensioning and social exclusion (Bryngelson, 2009). It is therefore important to identify risk factors in order to design rational preventive strategies.

Internalizing disorders (i.e., anxiety and mood disorders) are common, with a lifetime prevalence of $20-30 \%$ (Kessler et al., 2005a; Kringlen et al., 2006) and are associated with sick leave in prospective studies (Jenkins, 1985; Laitinen-Krispijn \& Bijl, 2000). Measures of psychological distress comprise symptoms of internalizing disorders and also predict sick leave (Duijts et al., 2007; Knudsen et al., 2013; Roelen et al., 2014; Terluin et al., 2011).

Patients can be granted sick leave for internalizing disorders, but having internalizing disorders or experiencing psychological distress may also increase the risk of sick leave granted for other mental as well as somatic disorders. Internalizing disorders are likely to predict sick leave granted

RECEIVED 17 January 2014; ACCEPTED 3 April 2014. First published online 14 May 2014.

ADDRESS FOR CORRESPONDENCE: Fartein A. Torvik, Norwegian Institute of Public Health, Box 4404, Nydalen N-0403, Oslo, Norway. E-mail: fartein.ask.torvik@fhi.no 
for other mental disorders because there is substantial comorbidity for most mental disorders (Kessler et al., 2005b). Whether internalizing disorders or distress also predict sick leave granted for somatic disorders has been unclear. It has been found that psychological distress predicts disability pensions granted for somatic disorders (Mykletun et al., 2006), but results from previous studies on sick leave are conflicting (Hensing \& Spak, 1998; Stansfeld et al., 2011). Such an association is, however, plausible: First, there is uncertainty associated with the diagnosis on the sick leave certificate (Maeland et al., 2012). Usually, only one diagnosis will be given, while the patient might suffer from comorbid somatic and mental disorders. Sick leave may be granted for a somatic disorder even though the patient's main complaints arise from mental issues. Second, internalizing disorders or psychological distress may reduce the ability to work when suffering from a somatic condition or make the patient pay more attention to somatic distress. For example, the higher rates of somatization among individuals with internalizing disorders (Terluin et al., 2011) could lead to more sick leaves granted for somatic disorders.

If an association exists between internalizing disorders or psychological distress and sick leave, twin studies can be used to determine to what degree the association is due to common genetic and/or environmental factors. In twin studies, variation in traits and covariation between traits are partitioned into three sources: genetic factors, environmental factors shared by twins, and non-shared environmental factors. Environmental covariation implies that environmental factors that influence internalizing disorders or psychological distress also have an effect on sick leave. Adverse life events are one possible example of such factors. Likewise, covariation ascribable to genetic factors refers to genes affecting both internalizing disorders or distress and sick leave. An example is genes contributing to comorbidity between internalizing disorders and the disorders for which sick leave is granted.

Internalizing disorders have been found to be influenced by genetic factors in a number of twin studies, with heritability estimates typically ranging between $30 \%$ and $60 \%$ (Bouchard, 2004; Kendler et al., 2003). Genetic risk factors are primarily shared for internalizing disorders and psychological distress (Gjerde et al., 2011). There is also a familial aggregation of sick leave. Two twin studies have found that this is mainly due to genetic and not environmental factors, and have estimated the heritability to $36 \%$ (Svedberg et al., 2012) and 49\% (Gjerde et al., 2013). As sick leave is a culturally specific construct, it is likely to share genetic risk factors with various disorders and possibly be influenced by the individuals' psychological characteristics. It is thus possible that some of the genetic factors that influence internalizing disorders and psychological distress also affect sick leave. Likewise, environmental events increasing the risk for internalizing disorders could also increase the risk for sick leave.
In the current study, prospective data from a large, population-based sample of young adult twins were used to (1) estimate the degree to which internalizing disorders and clinical levels of psychological distress are associated with sick leave granted for mental disorders and sick leave granted for somatic disorders, and (2) investigate the extent to which common underlying genetic and environmental factors can account for these associations.

\section{Materials and Methods}

\section{Sample and Assessment}

The sample for the current study originated from the Norwegian Institute of Public Health Twin Panel (NIPHTP). Twins were identified through the National Medical Birth Registry, established on January 1, 1967. The participants selected for the current study were twins born between 1967 and 1979, who took part in a large questionnaire study in 1998, and a subsample who later underwent diagnostic interviews for mental disorders. These data were linked to longitudinal registry data from Statistics Norway (2013) on sick leave, including diagnoses from 2000 to 2008. The NIPHTP is thoroughly described elsewhere (Nilsen et al., 2012).

All twins born between 1967 and 1979 who were alive and had a known address in 1998 were invited to complete a questionnaire. Out of 12,700 invited twins, 8,045 (63\%) responded after one reminder. The diagnostic interview was conducted between June 1999 and May 2004 (approximately $90 \%$ within the end of 2002) among a subsample of complete twin pairs who had responded to the questionnaire and had given consent to be contacted again later. Due to technical problems, 68 twin pairs were drawn directly from NIPHTP. The response rate was 44\% (2,801 out of 6,306). Analyses of attrition from the questionnaire to the interview study found that out of 45 potential predictors, only older age and monozygosity predicted participation, and that this did not substantially affect estimates of genetic and environmental contributions to mental health related variables (Tambs et al., 2009).

Of the main sample, 7,710 twins were linked to sick leave data, while 335 withdrew from the study. A further 12 twins were excluded due to lack of data on zygosity. The sample of 7,698 twins included 3,108 complete pairs (492 monozygotic [MZ] male, 354 dizygotic [DZ] male, $759 \mathrm{MZ}$ female, $607 \mathrm{DZ}$ female, and 896 opposite sex twin pairs) and 1,482 singletons, of which 2,766 had been interviewed (1,365 complete pairs [217 MZ male, 118 DZ male, 435 MZ female, $260 \mathrm{DZ}$ female] and 335 opposite sex twin pairs), and 36 single responders. Valid data were available for 7,295 twins, of whom 2,677 were interviewed. In total, $42.1 \%$ were males. Age at the start of follow-up (year 2000) spanned from 20 to 32 years $($ mean $=26.5)$. Figure 1 depicts a flowchart of the recruiting and drop-out of participants. 


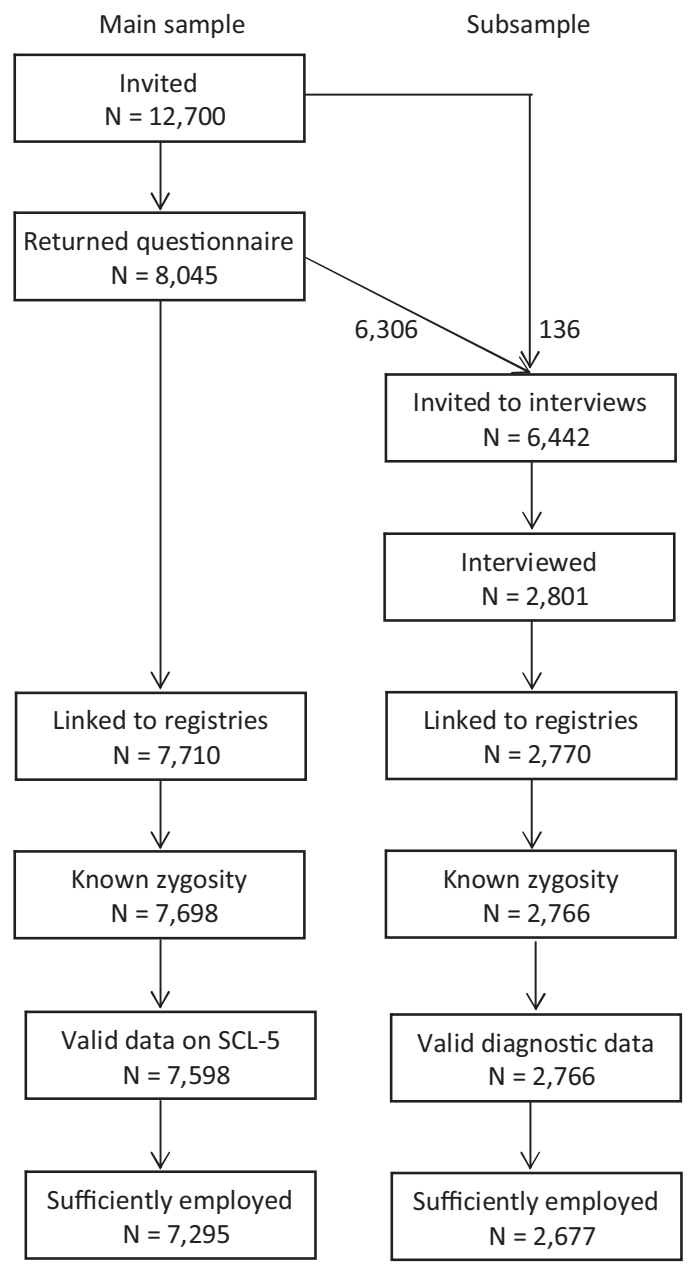

\section{FIGURE 1}

Participants in the study, main sample, and subsample. All twins with known zygosity are included in the analyses.

Zygosity was initially determined using questionnaire items previously shown to correctly classify more than $97 \%$ of the twin pairs (Magnus et al., 1983), followed by DNA analyses on a subgroup of the sample. The discrepancy between classification based on the questionnaire and DNA markers implied an expected misclassification rate of approximately $2 \%$ for the whole sample, which is unlikely to bias our results (Neale, 2003).

\section{Ethics}

The linkage of data from NIPHTP with registries at Statistics Norway (2013) was approved by the Regional Ethical Committee. For the interview study, approval was received from the Regional Ethical Committee and the Norwegian Data Inspectorate, and written informed consent was obtained from the participants after complete description of the study.

\section{Measures}

Both a diagnostic interview and a short self-report measure of psychological distress were included as measures of internalizing disorders, or an approximation to these. Although structured diagnostic interviews are considered superior to short self-report scales, the self-report scale covered a larger sample and was measured prospectively, while the interviews were conducted after the registration of sick leave had started.

Self-reported symptoms of psychological distress. The Symptom Checklist-5 (SCL-5; Tambs \& Moum, 1993) measures symptoms of anxiety and depression. This is a shortened version of SCL-25 (Hesbacher et al., 1980), which has been found to correlate 0.92 with the full-scale version (Tambs \& Moum, 1993). The SCL-5 consists of five items addressing how the subject has felt for the last 14 days, responded to on a 4-point scale with anchors 1 (not at all) to 4 (extremely). The internal consistency of the SCL-5, measured by Cronbach's alpha, was 0.83 in the present sample. The variable was dichotomized applying the recommended cut-off of 2.0 (Müller et al., 2010).

Diagnostic interview. The Norwegian version of the computerized Munich Composite of International Diagnostic Interview (CIDI; Wittchen \& Pfister, 1997) was applied. This is a structured diagnostic interview developed by the World Health Organization for the assessment of the Diagnostic and Statistical Manual of Mental Disorders (DSM)IV Axis I diagnoses and the International Classification of Diseases (ICD)-10 lifetime diagnoses. The interview has previously shown good test-retest and inter-rater reliability (Wittchen, 1994; Wittchen et al., 1998). The interviews were mainly conducted by psychology students late in their training and psychiatric nurses who completed a standardized training program by teachers certified by the WHO. Co-twins were assessed by different interviewers. Most of the interviews $(2,562)$ were conducted face to face, but for practical reasons 231 were interviewed over the phone. In order to investigate the broad construct of internalizing disorders, the following lifetime disorders were selected for the present study: major depressive disorder, dysthymia, generalized anxiety disorder, social phobia, panic disorder, and agoraphobia. As these disorders are strongly interrelated (Hettema et al., 2006; Krueger \& Markon, 2006; Røysamb et al., 2011), a dichotomized index (no lifetime internalizing disorder vs. any lifetime internalizing disorder) was generated based on the specific diagnostic data.

Employment and sick leave. The Historical-Event Database contains data for the entire population (1992 and onwards) regarding employment, taxation, and social security benefits, including sickness benefits exceeding 16 days (covered by the mandatory Norwegian Insurance Scheme), rehabilitation allowance, and disability pensioning 
(Akselsen et al., 2007). Shorter sick leaves were not included in this study. After 52 weeks, an individual who is unable to work is sometimes granted rehabilitation allowance (Norwegian Official Reports, 2000), and these periods were included as they reflect a continuation of sick leave. For each day from January 1, 2000 to December 31, 2008, we had information on whether each participant was registered as employed, on sick leave, and/or on rehabilitation, and if applicable also diagnoses. Diagnoses set by physicians were coded according to the International Classification of Primary Care (WONCA, 2005). Diagnoses in the P-chapter were coded as mental, whereas all other diagnoses were coded as somatic. As the degree of employment varied between individuals, the sick leave variables were defined as a ratio $(0-100 \%)$ of days lost to sick leave or rehabilitation granted for mental or somatic disorders to the number of potential working days. Thus, only time registered as employed was counted, and not, for example, time spent as full-time student, abroad, or after permanent disability pensioning. Sick leave days with unknown diagnosis $(0.4 \%)$ were excluded. Sick leave proportions were divided into four categories, as these variables were positively skewed. The first category comprised those individuals without sick leave in the period, while cut-off values for the three other categories were chosen to apply to groups with a similar number of cases (for sick leave granted for somatic disorders, cut-offs were 2.4 and $9.3 \%$ of working days lost to sick leave; for sick leave granted for mental disorders, cut-offs were 2.8 and 9.5\%). Repeated occurrences of sick leave make it possible to score positive on both sick leave variables. Sick leave was only defined for individuals who had been employed for at least 365 days during the period $(97.0 \%)$.

\section{Statistical Analyses}

The association between internalizing disorders or psychological distress and sick leave was assessed by calculating polychoric correlations and through logistic regressions adjusting for non-independence between twins in a pair (General Estimating Equations [GEE]). The analyses were run using the 'polychor' (Fox, 2010) and 'gee' (Carey et al., 2012) packages for $\mathrm{R}$ ( $\mathrm{R}$ Core Team, 2012) respectively. The logistic regressions were used to assess the probability of being in the group with the highest level of sick leave on each sick leave variable. Effects of differences within twin pairs (fixed effects, clustered on twin pair identity) were estimated to adjust for familial effects (genetic and shared environmental; Carlin et al., 2005). In the absence of nonshared confounders, effects of differences within MZ twin pairs approach causal effects (Frisell et al., 2012; McGue et al., 2010). These analyses were stratified by zygosity.

Trivariate Cholesky models (Neale \& Maes, 2004) were fitted to the data to investigate genetic and environmental covariance between internalizing disorders or psychological distress and sick leave granted for mental and somatic disorders. One set of models was estimated with the SCL-5 data and another set with interview data, both with two sick leave variables (mental vs. somatic diagnoses). When using ordinal data, thresholds distinguishing between the categories must be estimated (liability-threshold models). First, we ran a fully saturated model with specific thresholds for each twin in each zygosity group and tested whether thresholds could be constrained to be equal across twins in a pair, across zygosity, and across sexes. We then specified Cholesky decompositions with all three latent sources of variance: A, C, and E. Multivariate ACE Cholesky models allow for qualitative and quantitative sex differences to be tested (Neale et al., 2006). Qualitative sex differences involve different genetic and/or environmental effects for males and females (general sex limitation [GSL] model), while quantitative sex effects involve the same genetic and environmental structure for men and women, but with different effect sizes for the sexes (common sex limitation model [CSL]). These models are compared with a model constraining the parameters to be equal across sex (no sex limitation model [NSL]). After testing for qualitative sex differences in additive genetic factors and quantitative sex differences, we ran submodels to test for the significance of $A$ and $C$ parameters by fixing selected parameters to be zero in $\mathrm{AE}, \mathrm{CE}$ and $\mathrm{E}$ models consecutively.

The models were fitted using the Full Information Maximum Likelihood (FIML) as estimation procedure to raw data in OpenMx (Boker et al., 2011). The raw data method utilizes data from both complete and incomplete pairs, which increases accuracy. All twins with known zygosity were included in the analyses. The difference in -2 times log likelihood $(\Delta-2 \mathrm{LL})$ is asymptotically $\chi^{2}$ distributed, which allows testing for significant differences in $\chi^{2}$ for nested submodels. If the difference in $\chi^{2}$ is non-significant, a simpler, more restricted model is preferred. In addition, we used the Akaike Information Criterion (AIC) as an index of parsimony (Akaike, 1987). Models with low AIC value are preferred.

\section{Results}

The prevalence of clinical levels of psychological distress during the past 2 weeks was $11.6 \%$ (8.6\% for men and $13.8 \%$ for women) whereas $19.9 \%$ of those attending the interview scored positive for any lifetime internalizing disorder (14.2\% for men, $23.2 \%$ for women). Overall, $2.5 \%$ of all working days were lost to sick leave granted for mental disorders ( $1.4 \%$ for men; $3.3 \%$ for women) and $6.9 \%$ to sick leave granted for somatic disorders (4.1\% for men; $8.9 \%$ for women). Distribution of the sample on the included variables is shown in Table 1.

Any lifetime internalizing disorder and self-reported psychological distress correlated 0.49 (95\% CI 0.42-0.55). Any lifetime internalizing disorders were more strongly associated with sick leave granted for mental disorders 


\section{TABLE 1}

Characteristics of the Sample

\begin{tabular}{lrr}
\hline & \multicolumn{2}{c}{$n$ (valid \%) } \\
\hline Sex & & \\
$\quad$ Male & 3,241 & $(42.1 \%)$ \\
$\quad$ Female & 4,457 & $(57.9 \%)$ \\
Clinical levels of psychological distress (SCL-5) & 6,714 & $(88.4 \%)$ \\
$\quad$ No & 884 & $(11.6 \%)$ \\
$\quad$ Yes & 100 & \\
Missing & & \\
Any lifetime internalizing disorder (CIDI) & 2,217 & $(80.2 \%)$ \\
$\quad$ No & 549 & $(19.8 \%)$ \\
Yes & 4,932 & \\
Missing & & \\
Sick leave granted for mental disorders & 6,064 & $(82.1 \%)$ \\
No (0\% of workdays) & 449 & $(6.1 \%)$ \\
Some (0-2.4\% of workdays) & 449 & $(6.1 \%)$ \\
Medium (2.4-9.3\% of workdays) & 421 & $(5.7 \%)$ \\
High (>9.3\% of workdays) & 315 & \\
Missing & & \\
Sick leave granted for somatic disorders & 3,204 & $(43.3 \%)$ \\
$\quad$ No (0\% of workdays) & 1,406 & $(19.0 \%)$ \\
Some (0-2.8\% of workdays) & 1,403 & $(19.0 \%)$ \\
Medium (2.8-9.5\% of workdays) & 1,370 & $(18.6 \%)$ \\
High ( $>9.5 \%$ of workdays) & 315 & \\
Missing & & \\
\hline
\end{tabular}

( $r=0.45,95 \%$ CI $0.38-0.51)$ than was psychological distress ( $r=0.34,95 \%$ CI 0.29 to 0.39 ). However, both measures of internalizing disorders and/or psychological distress were associated with sick leave granted for somatic disorders to approximately the same degree $(r=0.17,95 \%$ CI $0.11-0.23$, and $r=0.18,95 \%$ CI $0.13-0.22$ ).

Logistic regression analyses (Table 2) showed that individuals who screened positive on the SCL or had any lifetime internalizing disorder were more likely to be in the group with the highest level of sick leave granted for mental disorders, with sex- and age-adjusted odds ratios (ORs) 4.00 and 6.43 respectively. Individuals who screened positive on SCL or had any lifetime internalizing disorder were also more likely to have higher rates of sick leave granted for somatic disorders, with ORs of 1.76 and 1.73 respectively. Analyses of effects within twin pairs (fixed effects) showed that $\mathrm{MZ}$ twins who had clinical levels of psychological distress or any lifetime internalizing disorder were more likely to have high levels of sick leave granted for mental disorders than their discordant co-twins (ORs of 4.03 and 4.80 respectively). However, MZ twins with clinical levels of psychological distress or any lifetime internalizing disorder did not have statistically significantly elevated rates of sick leave granted for somatic disorders, compared with their co-twins (ORs at 1.24 and 0.88$)$.

\section{Model Fitting}

Self-reported psychological distress (SCL-5). Results from the model fitting with SCL-5 and the two sick leave variables are shown in Table 3. Initial tests of invariance showed that it was possible to constrain the thresholds to be equal across twin order and zygosity groups $(\Delta-2 \mathrm{LL}=$ 61.91, $\Delta d f=56, p=.273)$, but not across gender $(\Delta-2 \mathrm{LL}$
$=843.02, \Delta d f=63, p<.001)$, as also implied by the higher female prevalence. Thus, all Cholesky models were fitted with one set of thresholds for men and one set of thresholds for women. The ACE CSL model (II) had a better AIC fit and not significantly higher -2LL than ACE GSL model. The model fit further improved when fixing all effects of shared environment to zero (model III), whereas omitting A (CE model) substantially reduced model fit (model IV). Fixing all paths to be equal for men and women (no sex limitation; NSL) improved the model fit (model VI) compared with the ACE CSL model. The fit improved even more when removing C from the NSL model (model VII). A could not be removed from the NSL model (model VIII). The best fitting model was the AE model with no sex limitation $(\mathrm{AIC}=-11719.82, \Delta-2 \mathrm{LL}=14.18, \Delta d f=18, p=$ .717 compared with the initial ACE GSL model).

Any lifetime internalizing disorder (CIDI). For the model fitting that included interview data, the same steps were followed as for model fitting with SCL-5 (Table 4). Invariance tests showed that thresholds could be set equal across twin order and zygosity group $(\Delta-2 \mathrm{LL}=65.13$, $\Delta d f=56, p=.189)$, but different sets of thresholds were needed for men and women $(\Delta-2 \mathrm{LL}=868.89, \Delta d f=63, p$ $<.001)$. Again, the best fitting and the most parsimonious model was the AE model without sex differences (AIC = -4683.77, $\Delta-2 \mathrm{LL}=26.90, \Delta d f=18, p=.081$, compared with the ACE GSL model).

Path estimates of the best fitting models. The best fitting model with path estimates for SCL- 5 and sick leave is shown in Figure 2, while the estimates from the best fitting model with the diagnostic interviews are shown in Figure 3. The genetic and environmental factors influencing internalizing disorders or psychological distress (A1 and E1) had a significant impact on sick leave granted for mental disorders. These associations were somewhat stronger for the interview data than for the SCL-5 self-report data. The genetic factors involved in internalizing disorders or distress (A1) also had an effect on sick leave granted for somatic disorders. However, there were no statistically significant environmental paths (through E1) connecting internalizing disorders or distress and sick leave granted for somatic disorders. Finally, there were significant genetic paths (through A1 and A2), but no significant environmental paths (through E1 and E2) connecting sick leave granted for mental and somatic disorders. Except for the interview data being more strongly correlated with sick leave granted for mental disorders than for SCL-5 self-report data, the path estimates were similar for the two measures.

\section{Discussion}

The most important findings of this study were that individuals with internalizing disorders had higher rates of 
TABLE 2

The Relationship Between Internalizing Disorders or Psychological Distress and Sick Leave Odds Ratios (OR) for Being in the Group With the Highest Level of Sick Leave

\begin{tabular}{|c|c|c|c|c|c|c|c|c|}
\hline & \multirow[b]{2}{*}{ N } & \multirow{2}{*}{$\begin{array}{l}\text { Discor-dant } \\
\text { pairs }\end{array}$} & \multicolumn{2}{|c|}{$\begin{array}{l}\text { Sick leave granted for } \\
\text { mental disorders }\end{array}$} & \multirow[b]{2}{*}{$p$} & \multicolumn{2}{|c|}{$\begin{array}{l}\text { Sick leave granted for } \\
\text { somatic disorders }\end{array}$} & \multirow[b]{2}{*}{$p$} \\
\hline & & & OR & $95 \% \mathrm{Cl}$ & & OR & $95 \% \mathrm{Cl}$ & \\
\hline \multicolumn{9}{|c|}{ Clinical levels of psychological distress } \\
\hline Unpaired analyses & 7,295 & & 4.00 & {$[3.18-5.04]$} & $<.001$ & 1.76 & {$[1.48-2.09]$} & $<.001$ \\
\hline Within DZ twin pairs & 3,368 & 297 & 2.40 & {$[1.36-4.23]$} & .003 & 1.93 & {$[1.29-2.89]$} & .001 \\
\hline Within MZ twin pairs & 2,288 & 148 & 4.03 & [1.59-10.20] & .003 & 1.24 & {$[0.72-2.12]$} & .434 \\
\hline \multicolumn{9}{|c|}{ Any lifetime internalizing disorder } \\
\hline Unpaired analyses & 2,677 & & 6.43 & {$[4.51-9.16]$} & $<.001$ & 1.73 & {$[1.37-2.19]$} & $<.001$ \\
\hline Within DZ twin pairs & 1,334 & 194 & 2.80 & {$[1.29-6.07]$} & .009 & 2.36 & {$[1.45-3.84]$} & $<.001$ \\
\hline Within MZ twin pairs & 1,232 & 138 & 4.80 & {$[1.82-12.65]$} & .002 & 0.88 & {$[0.52-1.48]$} & .622 \\
\hline
\end{tabular}

Note: Unpaired and paired (fixed effects) results from logistic regression with generalized estimating equations, adjusted for sex and age.

\section{TABLE 3}

Results of the Cholesky Model Fitting With Self-Reported Psychological Distress (SCL-5) and Sick Leave Granted for Mental and Somatic Disorders Among 7,698 Individuals (2,828 Complete Pairs With No Missing Data)

\begin{tabular}{|c|c|c|c|c|c|c|c|}
\hline \multicolumn{2}{|c|}{ Model no. and name } & \multirow{2}{*}{$\begin{array}{l}\text { Ep. } \\
56\end{array}$} & \multirow{2}{*}{$\frac{-2 \mathrm{LL}}{33080.00}$} & \multirow{2}{*}{$\frac{d f}{22,389}$} & \multirow{2}{*}{$\frac{\text { AIC }}{-11698.00}$} & \multirow{2}{*}{$p$} & \multirow{2}{*}{$\frac{\text { Comparison }}{-}$} \\
\hline I & ACE GSL & & & & & & \\
\hline II & ACE CSL & 50 & 33081.89 & 22,395 & -11708.11 & .930 & I \\
\hline III & AE CSL & 38 & 33092.92 & 22,404 & -11715.08 & .274 & ॥ \\
\hline IV & CE CSL & 38 & 41439.46 & 22,404 & -3368.54 & $<.001$ & ॥ \\
\hline V & E CSL & 26 & 45665.00 & 22,413 & 839.00 & $<.001$ & II \\
\hline VI & ACE NSL & 32 & 33086.45 & 22,401 & -11715.55 & .600 & ॥ \\
\hline VII & AE NSL & 26 & 33094.18 & 22,407 & -11719.82 & .259 & VI \\
\hline VIII & CE NSL & 26 & 33124.63 & 22,407 & -11689.37 & $<.001$ & $\mathrm{VI}$ \\
\hline IX & E NSL & 20 & 41551.79 & 22,413 & -3274.21 & $<.001$ & $\mathrm{VI}$ \\
\hline
\end{tabular}

Note: $\mathrm{A}=$ additive genetic effects; $\mathrm{C}=$ shared environmental effects; $\mathrm{E}=$ non-shared environmental effects; $\mathrm{CSL}=\mathrm{common}$ (scalar) sex limitation; NSL = no sex limitation.

Bold type indicates the best fitting model.

\section{TABLE 4}

Results of the Cholesky Model Fitting With Lifetime Internalizing Disorders (CIDI) and Sick Leave Granted for Mental and Somatic Disorders Among 2,766 Individuals (1,283 Complete Pairs With No Missing Data)

\begin{tabular}{llllllll}
\hline Model no. and name & Ep. & -2LL & df & AIC & $p$ & Comparison \\
\hline I & ACE GSL & 56 & 30439.33 & 17,557 & -4674.67 & - & - \\
II & ACE CSL & 50 & 30448.60 & 17,563 & -4677.40 & .159 & I \\
III & AE CSL & 38 & 30462.60 & 17,572 & -4681.40 & .122 & II \\
IV & CE CSL & 38 & 33747.55 & 17,572 & -1396.45 & $<.001$ & II \\
V & E CSL & 26 & 35300.72 & 17,581 & 138.72 & $<.001$ & II \\
VI & ACE NSL & 32 & 30455.28 & 17,569 & -4682.72 & .351 & II \\
VII & AE NSL & 26 & 30466.23 & 17,575 & -4683.77 & .090 & VI \\
VIII & CE NSL & 26 & 31532.04 & 17,575 & -3617.96 & $<.001$ & VI \\
IX & E NSL & 20 & 39551.52 & 17,581 & 4389.52 & $<.001$ & VI \\
\hline
\end{tabular}

Note: $\mathrm{A}=$ additive genetic effects; $\mathrm{C}=$ shared environmental effects; $\mathrm{E}=$ non-shared environmental effects; $\mathrm{CSL}=\mathrm{common}$ (scalar) sex limitation; NSL = no sex limitation.

Bold type indicates the best fitting model.

sick leave granted for both mental and somatic disorders over a period of 9 years, and that the correlation between internalizing disorders and sick leave granted for mental disorders can be accounted for by both genes and unshared environmental factors. The association between internalizing disorders and sick leave granted for somatic disorders appeared to be entirely due to a common genetic factor. Environmental factors influencing internalizing disorders did not significantly influence sick leave granted for somatic disorders. The association between internalizing disorders and sick leave granted for mental disorders was due to both genetic and environmental factors. No effects of shared environment were found. The results were approximately the same for the self-reported psychological distress measure and the internalizing disorders diagnosed by interviews. This discussion will therefore apply the term 'internalizing disorders' unless the results vary between the two measures. 


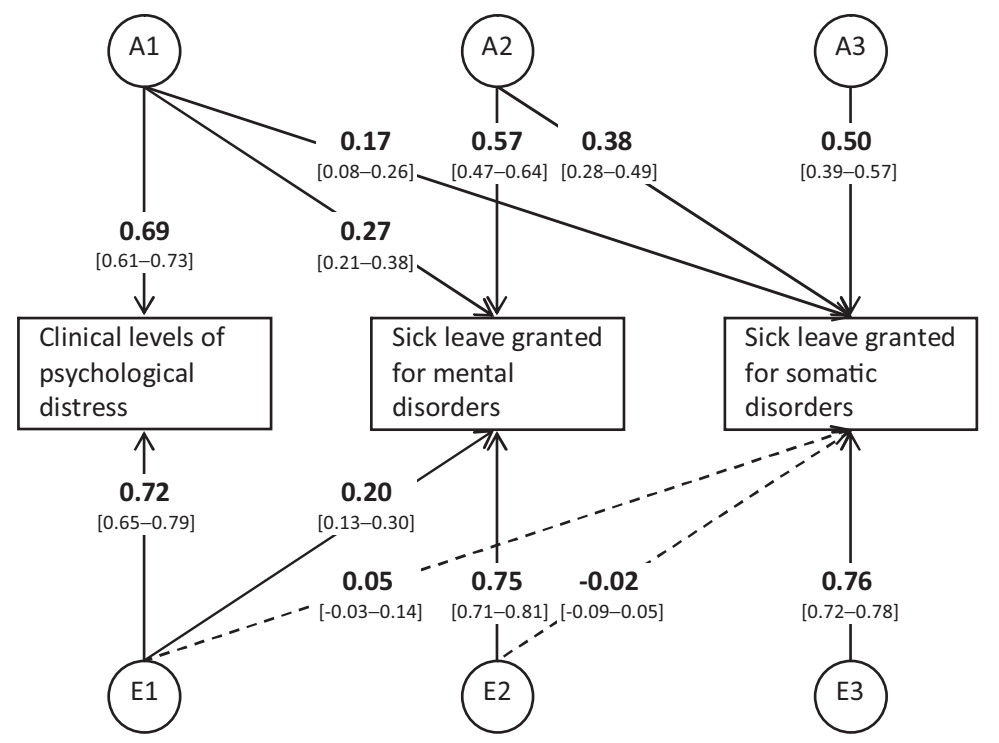

\section{FIGURE 2}

Diagram over the best fitting model (Cholesky AE, no sex limitation) of clinical levels of psychological distress (SCL-5) and sick leave granted for mental and somatic disorders. Path estimates for additive genetic (A) and non-shared environmental (E) factors, including $95 \%$ confidence intervals.

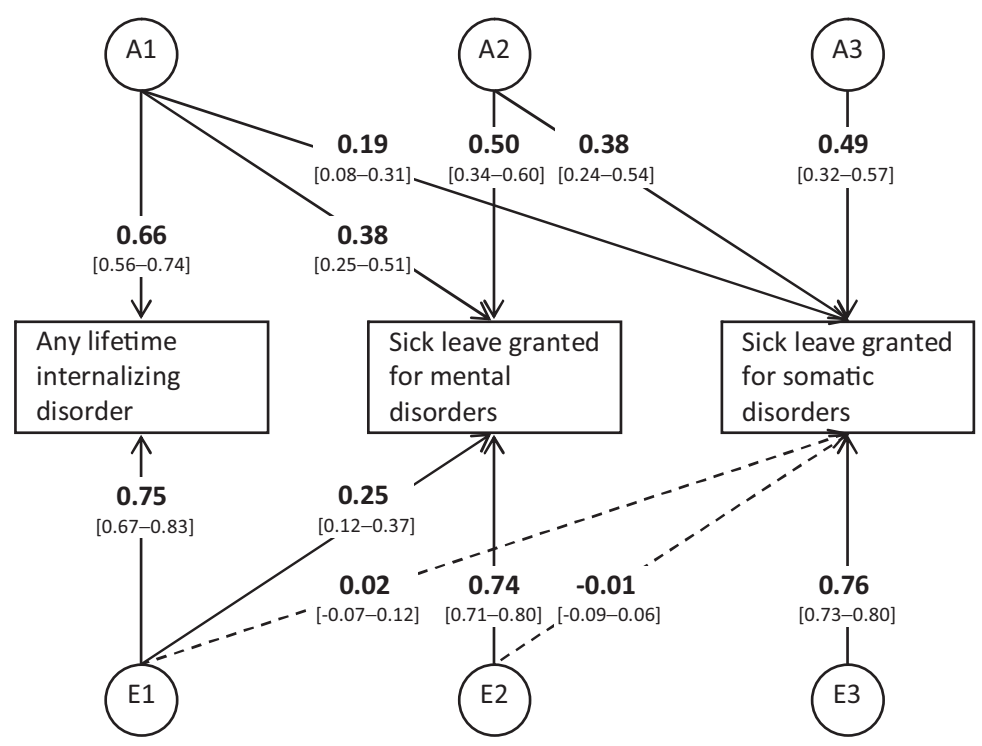

\section{FIGURE 3}

Diagram over the best fitting model (Cholesky AE, no sex limitation) of any lifetime internalizing disorder (CIDI) and sick leave granted for mental and somatic disorders. Path estimates for additive genetic (A) and non-shared environmental (E) factors, including $95 \%$ confidence intervals.

As sick leave can be granted for internalizing disorders, it was expected that internalizing disorders were strong predictors of sick leave granted for mental disorders. Lifetime internalizing disorder predicted sick leave granted for mental disorders more strongly than did psychological distress. This is not surprising because sick leave can be granted for internalizing disorders, but not psychological distress per se. Participants with internalizing disorders also had elevated rates of sick leave granted for somatic disorders. These results are in accordance with previous studies finding that symptoms of internalizing disorders predict sick leave in general as well as sick leave and disability pensions granted for somatic disorders (Hensing \& Spak, 1998; Knudsen et al., 2013; Mykletun et al., 2006).

These observed associations can reflect causal relationships or common risk factors. Phenotypic causation implies that one variable affects another variable (e.g., that internalizing disorders renders a person unable to work) 
regardless of what causes the first variable. When each of the phenotypes is influenced by both genetic and environmental factors, as the phenotypes in this case, phenotypic causation implies that both genetic and environmental associations exist between the phenotypes (Ligthart \& Boomsma, 2012). Although common environmental and genetic influences do not necessarily imply that the variables are causally related (Neale \& Kendler, 1995), the present findings on internalizing disorders and sick leave granted for mental disorders are consistent with phenotypic causation; that is, internalizing disorders lead to sick leave granted for mental disorders. Interestingly, there was a different pattern for sick leave granted for somatic diagnoses. There were no significant environmental associations between internalizing disorders and sick leave granted for somatic disorders. Non-significant findings do not rule out the existence of small effects. Nevertheless, the present results are not consistent with phenotypic causation of sick leave granted for somatic disorders by internalizing disorders over extended periods of time. Fixed effect results from the co-twin analyses also reflect these findings, as internalizing disorders and sick leave granted for mental disorders were not significantly associated within MZ twin pairs.

Common genetic factors alone could account for the association between internalizing disorders and sick leave granted for somatic disorders. At least part of this genetic correlation could be due to a genetically influenced comorbidity between internalizing disorders and the somatic conditions for which sick leave is granted. Many health problems, including medically unexplained somatic symptoms, are more frequent among people with anxiety and depression than among those without anxiety and depression (Prince et al., 2007). Common genetic vulnerabilities have also been established between internalizing disorders and a range of somatic conditions, including both pain and coronary artery disease (Kato et al., 2006; McCaffery et al., 2006; Reichborn-Kjennerud et al., 2002). In addition, people with a somatic disorder may be more likely to obtain sick leave when also having an internalizing disorder or high levels of psychological distress (Allebeck \& Mastekaasa, 2004; Krokstad, 2002). Coping skills, for example, influence whether somatic conditions lead to sick leave (Werner \& Cote, 2009). Personality, and especially neuroticism, is also likely to affect sick leave granted for somatic disorders: Neuroticism is related to both internalizing disorders and a range of somatic health conditions, possibly due to chronic activation of stress response (Charles et al., 2008). Neuroticism may also be related to higher sensitivity to pain or other negative stimuli (Canli et al., 2001; Goubert et al., 2004). Charles et al. (2008) suggest that there could be a genetic pathway between neuroticism and pain experiences. Indeed, people high in neuroticism have higher rates of sick leave, even if they do not have any current psychopathology (Vlasveld et al., 2013). Neuroticism may moreover have an effect through its association with health anxiety (Williams, 2004).

Environmental factors that increased the liability to scoring above the threshold for internalizing disorders did not significantly affect sick leave granted for somatic disorders over the 9-year period. Nevertheless, the confidence intervals for these associations imply that an environmental association cannot be ruled out. Particularly, the lack of significant environmental association in this study does not exclude the possibility of an effect in the short run. Over a period as long as 9 years, fluctuating environmental events may even out the risk between twins to the level expected from their genetic similarity. Possible short-term effects of fluctuating environmental events can be investigated in future studies where sick leave is studied in shorter intervals. Alternatively, it is possible that environmental effects of internalizing disorders on sick leave granted for somatic disorders become more prominent with higher age. Neuroticism has been found to be a risk factor for disability pensioning granted for low back pain diagnoses, and family factors only play a minor role in that relationship (Ropponen et al., 2012). However, genetic effects seem to play a larger role for disability pensioning among young adults than among older individuals, and twin resemblance in disability pensioning decreases with time (Gjerde et al., 2013; Harkonmäki et al., 2008; Narusyte et al., 2011). Also, the pattern of association between sick leave and disability pensioning suggests phenotypic causation (Gjerde et al., 2013; Narusyte et al., 2014). Thus, it is possible that persistent internalizing disorders have a stronger environmental effect on sick leave granted for somatic disorders. This could be addressed in older twin samples.

Shared environment was not important in explaining sibling similarity in sick leave in our best fitting models. This is in line with previous twin studies on sick leave (Gjerde et al., 2013; Svedberg et al., 2012). Our findings therefore do not support social transmission of sick leave between family members. However, it should be noted that there is evidence of shared environmental effects on disability pensioning (Bratberg et al., 2013; Harkonmäki et al., 2008), which is a possible outcome of long-term sick leave.

The analyses showed approximately the same results for sick leave granted for somatic disorders regardless of whether internalizing disorders were observed as high SCL5 scores or in a diagnostic interview. This strengthens the validity of the results, as it is a form of method triangulation. The diagnostic interviews were more predictive of sick leave granted for mental disorders than was the selfreported psychological distress measure. Nevertheless, the five SCL questions predicted sick leave granted for somatic disorders as well as did the more comprehensive interview.

\section{Methodological Considerations}

This study had several strengths, such as data from a diagnostic interview, highly reliable registry data on sick leave, 
including diagnoses, a long follow-up period, and a genetically informative sample recruited from the general twin population. There are also some limitations. First, the sample consisted of young adults, which may limit generalizability to other age groups. Second, there could be health differences between twins and singletons. However, other twin samples have been found to be representative for the general population regarding several health, lifestyle, and personality measures (Andrew et al., 2001; Johnson et al., 2002), and the prevalence of mental disorders is approximately the same in our sample as other population-based studies (Gjerde et al., 2011; Kessler et al., 2005a). Third, the diagnostic interviews were conducted early in the follow-up period and could thus to some degree reflect consequences of sick leave. However, the self-reported psychological distress was measured several years before the sick leave and was equally strongly related to sick leave granted for somatic diagnoses. It is therefore unlikely that the association between any lifetime internalizing disorder and sick leave granted for somatic disorders is inflated. Fourth, only one diagnosis was available for each period of sick leave. Thus, we do not know whether physicians granting sick leave considered both mental and somatic disorders to be present. Fifth, this study did not include measures of somatic disorders, pain sensitivity, or personality, which may explain part of the relationship between the included variables. These variables should be investigated in future studies. Finally, the statistical power to detect shared environmental effect is rather low. The fact that we did not find such effects even with a quite large sample, such as ours, does not imply that effects of shared environment do not exist.

In conclusion, internalizing disorders among young adults indicated a risk not only of sick leave granted for mental disorders but also sick leave granted for somatic disorders. The genetic factor of internalizing disorders influenced sick leave granted for both mental and somatic disorders. The environmental factor of internalizing disorders was associated with sick leave granted for mental disorders, but did not seem to influence sick leave granted for somatic disorders among young adults. The results for sick leave granted for mental disorders are consistent with both phenotypic causation, most likely from internalizing disorders to sick leave, and genetic and environmental factors influencing both phenotypes. The results for sick leave granted for somatic disorders suggest that the phenotypic correlation between such sick leave and internalizing disorders is due to common genes, at least among young adults.

\section{Acknowledgments}

The work was supported by a grant from The Sickness Absence Research Programme at The Norwegian Research Council. The collection of twin data was also in part supported by previous grants from The Norwegian Research Council, The Norwegian Foundation for Health and
Rehabilitation, and The Norwegian Council for Mental Health. We are very grateful to the twins for their participation.

\section{References}

Akaike, H. (1987). Factor analysis and AIC. Psychometrika, 52, 317-332.

Akselsen, A., Lien, S., \& Siverstøl, Ø. (2007). FD-trygd. List of variables. Oslo, Norway: Statistics Norway.

Allebeck, P., \& Mastekaasa, A. (2004). Causes of sickness absence: Research approaches and explanatory models. Scandinavian Journal of Public Health, 63(Suppl.), 36-43.

Andrew, T., Hart, D. J., Snieder, H., de Lange, M., Spector, T. D., \& MacGregor, A. J. (2001). Are twins and singletons comparable? A study of disease-related and lifestyle characteristics in adult women. Twin Research, 4, 464-477.

Boker, S., Neale, M., Maes, H., Wilde, M., Spiegel, M., Brick, T., ... Fox, J. (2011). OpenMx: An open source extended structural equation modeling framework. Psychometrika, 76, 306-317.

Bouchard, T. J. (2004). Genetic influence on human psychological traits. A survey. Current Directions in Psychological Science, 13, 148-151.

Bratberg, E., Nilsen, Ø. A., \& Vaage, K. (2013). Assessing the intergenerational correlation in disability pension recipiency. Bergen, Norway: Norwegian School of Economics.

Bryngelson, A. (2009). Long-term sickness absence and social exclusion. Scandinavian Journal of Public Health, 37, 839845.

Canli, T., Zhao, Z., Desmond, J. E., Kang, E., Gross, J., \& Gabrieli, J. D. E. (2001). An fMRI study of personality influences on brain reactivity to emotional stimuli. Behavioral Neuroscience, 115, 33-42.

Carey, V. J., Lumley, T., \& Ripley, B. (2012). GEE: Generalized estimation equation solver. Retrieved from http://cran.r-project.org/package=gee

Carlin, J. B., Gurrin, L. C., Sterne, J. A., Morley, R., \& Dwyer, T. (2005). Regression models for twin studies: A critical review. International Journal of Epidemiology, 34, 1089-1099.

Charles, S. T., Gatz, M., Kato, K., \& Pedersen, N. L. (2008). Physical health 25 years later: The predictive ability of neuroticism. Health Psychology, 27, 369-378.

Duijts, S. F., Kant, I., Swaen, G. M., van den Brandt, P. A., \& Zeegers, M. P. A. (2007). A meta-analysis of observational studies identifies predictors of sickness absence. Journal of Clinical Epidemiology, 60, 1105-1115.

Fox, J. (2010). Polycor: Polychoric and polyserial correlations. $\mathrm{R}$ package version 0.7-8. Retrieved from http://cran.r-project.org/package=polycor

Frisell, T., Oberg, S., Kuja-Halkola, R., \& Sjölander, A. (2012). Sibling comparison designs: Bias from non-shared confounders and measurement error. Epidemiology, 23, 713720 .

Gjerde, L. C., Knudsen, G. P., Czajkowski, N., Gillespie, N., Aggen, S. H., Røysamb, E., ... Orstavik, R. E. (2013). Genetic and environmental contributions to long-term sick 
leave and disability pension: A population-based study of young adult Norwegian twins. Twin Research and Human Genetics, 16, 759-766.

Gjerde, L. C., Røysamb, E., Czajkowski, N., ReichbornKjennerud, T., Orstavik, R. E., Kendler, K. S., \& Tambs, K. (2011). Strong genetic correlation between interviewassessed internalizing disorders and a brief self-report symptom scale. Twin Research and Human Genetics, 14, 64-72.

Goubert, L., Crombez, G., \& Van Damme, S. (2004). The role of neuroticism, pain catastrophizing and pain-related fear in vigilance to pain: A structural equations approach. Pain, 107, 234-241.

Harkonmäki, K., Silventoinen, K., Levälahti, E., Pitkäniemi, J., Huunan-Seppälä, A., Klaukka, T., .. Kaprio, J. (2008). The genetic liability to disability retirement: A 30-year follow-up study of 24,000 Finnish twins. PloS One, 3, e3402.

Hensing, G., \& Spak, F. (1998). Psychiatric disorders as a factor in sick-leave due to other diagnoses. A general populationbased study. The British Journal of Psychiatry, 172, 250-256.

Hesbacher, P. T., Rickels, K., Morris, R. J., Newman, H., \& Rosenfeld, H. (1980). Psychiatric illness in family practice. Journal of Clinical Psychiatry, 41, 6-10.

Hettema, J. M., Neale, M. C., Myers, J. M., Prescott, C. A., \& Kendler, K. S. (2006). A population-based twin study of the relationship between neuroticism and internalizing disorders. American Journal of Psychiatry, 163, 857-864.

Jenkins, R. (1985). Minor psychiatric morbidity in employed young men and women and its contribution to sickness absence. British Journal of Industrial Medicine, 42, 147-154.

Johnson, W., Krueger, R. F., Bouchard, T. J., \& McGue, M. (2002). The personalities of twins: Just ordinary folks. Twin Research, 5, 125-31.

Kato, K., Sullivan, P. F., Evengård, B., \& Pedersen, N. L. (2006). Chronic widespread pain and its comorbidities: A population-based study. Archives of Internal Medicine, 166, 1649-1654.

Kendler, K. S., Prescott, C. A., Myers, J., \& Neale, M. C. (2003). The structure of genetic and environmental risk factors for common psychiatric and substance use disorders in men and women. Archives of General Psychiatry, 60, 929-937.

Kessler, R. C., Berglund, P., Demler, O., Jin, R., Merikangas, K. R., \& Walters, E. E. (2005a). Lifetime prevalence and age-of-onset distributions of mental disorders in the National Comorbidity Survey Replication. Archives of General Psychiatry, 62, 593-602.

Kessler, R. C., Chiu, W. T., Demler, O., Merikangas, K. R., \& Walters, E. E. (2005b). Prevalence, severity, and comorbidity of 12-month DSM-IV disorders in the National Comorbidity Survey Replication. Archives of General Psychiatry, 62, 617-627.

Knudsen, A. K., Harvey, S. B., Mykletun, A., \& Overland, S. (2013). Common mental disorders and long-term sickness absence in a general working population. The Hordaland Health Study. Acta Psychiatrica Scandinavica, 127, 287297.
Kringlen, E., Torgersen, S., \& Cramer, V. (2006). Mental illness in a rural area: A Norwegian psychiatric epidemiological study. Social Psychiatry and Psychiatric Epidemiology, 41, 713-719.

Krokstad, S. (2002). Trends in health inequalities by educational level in a Norwegian total population study. Journal of Epidemiology \& Community Health, 56, 375-380.

Krueger, R. F., \& Markon, K. E. (2006). Reinterpreting comorbidity: A model-based approach to understanding and classifying psychopathology. Annual Review of Clinical Psychology, 2, 111-133.

Laitinen-Krispijn, S., \& Bijl, R. V. (2000). Mental disorders and employee sickness absence: The NEMESIS study. Social Psychiatry and Psychiatric Epidemiology, 35, 71-77.

Ligthart, L., \& Boomsma, D. I. (2012). Causes of comorbidity: Pleiotropy or causality? Shared genetic and environmental influences on migraine and neuroticism. Twin Research and Human Genetics, 15, 158-165.

Maeland, S., Werner, E. L., Rosendal, M., Jonsdottir, I. H., Magnussen, L. H., Ursin, H., \& Eriksen, H. R. (2012). Diagnoses of patients with severe subjective health complaints in Scandinavia: A cross-sectional study. ISRN Public Health, Article ID 85109, 1-9.

Magnus, P., Berg, K., \& Nance, W. E. (1983). Predicting zygosity in Norwegian twin pairs born 1915-1960. Clinical Genetics, 24, 103-112.

McCaffery, J. M., Frasure-Smith, N., Dubé, M.-P., Théroux, P., Rouleau, G. A., Duan, Q., \& Lespérance, F. (2006). Common genetic vulnerability to depressive symptoms and coronary artery disease: A review and development of candidate genes related to inflammation and serotonin. Psychosomatic Medicine, 68, 187-200.

McGue, M., Osler, M., \& Christensen, K. (2010). Causal inference and observational research: The utility of twins. Perspectives on Psychological Science, 5, 546-556.

Müller, J. M., Postert, C., Beyer, T., Furniss, T., \& Achtergarde, S. (2010). Comparison of eleven short versions of the Symptom Checklist 90-Revised (SCL-90-R) for use in the assessment of general psychopathology. Journal of Psychopathology and Behavioral Assessment, 32, 246-254.

Mykletun, A., Overland, S., Dahl, A. A., Krokstad, S., Bjerkeset, O., Glozier, N., . . Prince, M. (2006). A population-based cohort study of the effect of common mental disorders on disability pension awards. American Journal of Psychiatry, 163, 1412-1418.

Narusyte, J., Ropponen, A., Alexanderson, K., \& Svedberg, P. (2014). The role of familial factors in the associations between sickness Absence and disability pension or mortality. European Journal of Public Health, 24, 106-110.

Narusyte, J., Ropponen, A., Silventoinen, K., Alexanderson, K., Kaprio, J., Samuelsson, Å., \& Svedberg, P. (2011). Genetic liability to disability pension in women and men: A prospective population-based twin study. PloS One, 6, e23143.

Neale, M. C. (2003). A finite mixture distribution model for data collected from twins. Twin Research, 6, 235-239. 
Neale, M. C., \& Kendler, K. S. (1995). Models of comorbidity for multifactorial disorders. American Journal of Human Genetics, 57, 935-953.

Neale, M. C., \& Maes, H. H. M. (2004). Methodology for genetic studies of twins and families. Dordrecht, the Netherlands: Kluwer.

Neale, M. C., Røysamb, E., \& Jacobson, K. (2006). Multivariate genetic analysis of sex limitation and $\mathrm{G} \times \mathrm{E}$ interaction. Twin Research and Human Genetics, 9, 481-489.

Nilsen, T. S., Brandt, I., Magnus, P., \& Harris, J. R. (2012). The Norwegian Twin Registry. Twin Research and Human Genetics, 15, 775-780.

Norwegian Official Reports. (2000). Sykefraver og uførepensjonering - et inkluderende arbeidsliv [Sickness absence and disability pensioning - A labour market for all]. Oslo, Norway: Ministry of Labour.

OECD. (2010). Sickness, disability and work: Breaking the barriers. Paris, France: OECD.

Osterkamp, R., \& Röhn, O. (2005). Being on sick leave: Possible explanations for differences of sick-leave days across countries privatization. Ifo Working Paper, 19. Munich, Germany: Ifo Institute.

Prince, M., Patel, V., Saxena, S., Maj, M., Maselko, J., Phillips, M. R., \& Rahman, A. (2007). No health without mental health. Lancet, 370, 859-877.

R Core Team. (2012). R: A language and environment for statistical computing. Vienna, Austria: R Foundation for Statistical Computing. Retrieved from http://www.r-project.org/

Reichborn-Kjennerud, T., Stoltenberg, C., Tambs, K., Roysamb, E., Kringlen, E., Torgersen, S., \& Harris, J. R. (2002). Back-neck pain and symptoms of anxiety and depression: A population-based twin study. Psychological Medicine, 32, 1009-1020.

Roelen, C. A. M., Hoedeman, R., van Rhenen, W., Groothoff, J. W., van der Klink, J. J. L., \& Bültmann, U. (2014). Mental health symptoms as prognostic risk markers of all-cause and psychiatric sickness absence in office workers. European Journal of Public Health, 24, 101-105.

Ropponen, A., Svedberg, P., Huunan-Seppälä, A., Koskenvuo, K., Koskenvuo, M., Alexanderson, K., . . . Kaprio, J. (2012). Personality traits and life dissatisfaction as risk factors for disability pension due to low back diagnoses: A 30-year longitudinal cohort study of Finnish twins. Journal of Psychosomatic Research, 73, 289-294.

Røysamb, E., Tambs, K., Orstavik, R. E., Torgersen, S., Kendler, K. S., Neale, M. C., . . Reichborn-Kjennerud, T. (2011). The joint structure of DSM-IV Axis I and Axis II disorders. Journal of Abnormal Psychology, 120, 198-209.

Stansfeld, S. A, Fuhrer, R., \& Head, J. (2011). Impact of common mental disorders on sickness absence in an occupational cohort study. Occupational and Environmental Medicine, 68, 408-413.

Statistics Norway. (2013). Sykefravor, 3. kvartal 2013 [Sick leave, Q3 2013]. Retrieved March 1, 2014, from http://www.ssb.no/sykefratot/

Svedberg, P., Ropponen, A., Alexanderson, K., Lichtenstein, P., \& Narusyte, J. (2012). Genetic susceptibility to sickness absence is similar among women and men: Findings from a Swedish twin cohort. Twin Research and Human Genetics, $15,642-648$

Tambs, K., \& Moum, T. (1993). How well can a few questionnaire items indicate anxiety and depression? Acta Psychiatrica Scandinavica, 87, 364-367.

Tambs, K., Rønning, T., Prescott, C. A., Kendler, K. S., Reichborn-Kjennerud, T., Torgersen, S., \& Harris, J. R. (2009). The Norwegian Institute of Public Health twin study of mental health: Examining recruitment and attrition bias. Twin Research and Human Genetics, 12, 158-168.

Terluin, B., van Rhenen, W., Anema, J. R., \& Taris, T. W. (2011). Psychological symptoms and subsequent sickness absence. International Archives of Occupational and Environmental Health, 84, 825-837.

Vlasveld, M. C., van der Feltz-Cornelis, C. M., Anema, J. R., van Mechelen, W., Beekman, A. T. F., van Marwijk, H. W. J., \& Penninx, B. W. J. H. (2013). The associations between personality characteristics and absenteeism: A crosssectional study in workers with and without depressive and anxiety disorders. Journal of Occupational Rehabilitation, $23,309-317$.

Werner, E. L., \& Cote, P. (2009). Low back pain and determinants of sickness absence. The European Journal of General Practice, 15, 74-79.

Williams, P. G. (2004). The psychopathology of self-assessed health: A cognitive approach to health anxiety and hypochondriasis. Cognitive Therapy and Research, 28, 629644.

Wittchen, H. U. (1994). Reliability and validity studies of the WHO Composite International Diagnostic Interview (CIDI): A critical review. Journal of Psychiatric Research, 28, $57-84$.

Wittchen, H. U., Lachner, G., Wunderlich, U., \& Pfister, H. (1998). Test-retest reliability of the computerized DSM-IV version of the Munich-Composite International Diagnostic Interview (M-CIDI). Social Psychiatry and Psychiatric Epidemiology, 33, 568-578.

Wittchen, H., \& Pfister, H. (1997). DIA-X interviews (M-CIDI). Frankfurt, Germany: Swets \& Zeitlinger.

World Organization of Family Doctors (WONCA). (2005). ICPC-2-R: International classification of primary care. New York, NY: Oxford University Press. 